\title{
Wild Type and Omicron SARS-CoV-2 Spike Receptor Binding Domains Bind Similarly to the Human ACE2 Receptor: An MM-GBSA Study
}

Camryn Carter, ${ }^{\dagger}, 1$ Justin Airas ${ }^{\dagger 1,2}$ and Carol A. Parish ${ }^{1, *}$

${ }^{1}$ Department of Chemistry, Gottwald Center for the Sciences, University of Richmond, Richmond, VA 23173

${ }^{2}$ Department of Chemistry, Massachusetts Institute of Technology, Cambridge, MA 02139

${ }^{\dagger}$ Contributed equally to this work

*Corresponding Author

\begin{abstract}
SARS-CoV-2 is a coronavirus that has created a global pandemic. The virus contains a spike protein which has been shown to bind to the ACE2 receptor on the surface of human cells. Vaccines have been developed that recognize elements of the SARS-CoV-2 spike protein and they have been successful in preventing infection. Recently, the omicron variant of the SARS-CoV-2 virus was reported and quickly became a variant of concern due to its transmissibility. This variant contained an unusually large number (32) of point mutations, of which 15 of those mutations are in the receptor binding domain of the spike protein. In order to assess the differential binding ability of the wild type and omicron variant of the RBD spike protein to human ACE2 receptors, we conducted $2 \mu$ s of molecular dynamics simulation to estimate the binding affinities and behaviors. Based upon MM-GBSA binding affinity, center of mass distance measurements, ensemble clustering, pairwise residue decomposition and hydrogen bonding analysis, we can conclude that the 15 point mutations in the receptor binding domain do not increase the affinity of the spike protein for the human ACE2 receptor. The MM-GBSA binding estimations over a $2 \mu$ s trajectory, suggest that the wild type binds to ACE2 with a value of $-29.69 \mathrm{kcal} / \mathrm{mol}$ while the omicron mutant binds with an energy value of $-26.67 \mathrm{kcal} / \mathrm{mol}$. These values are within the error estimates of the MMGBSA method. While some mutations increase binding, more mutations diminish binding, leading to an overall similar picture of binding.
\end{abstract}




\section{Introduction}

Coronavirus disease-2019 (COVID-19) is a global pandemic caused by infection with the severe acute respiratory syndrome-coronavirus 2 (SARS-CoV-2). ${ }^{1-3}$ The virus has been circulating globally since late 2019, and has evolved genetically. ${ }^{4}$ In the first 11 months of the pandemic, viral mutations were occurring at a relatively slow rate; however, since late 2020 mutational variants of concern (VOC) have been identified. VOCs such as the alpha, beta, delta and omicron may be associated with enhanced viral fitness, and typically display increased transmissibility and infectivity characteristics. ${ }^{4-6}$

The SARS-CoV-2 virus encodes for a spike protein that contains a receptorbinding domain (RBD) that binds favorably to the ACE2 receptor present on the surface of human throat cells, and lung epithelial cells. ${ }^{7-8}$ This binding creates a fusion between the human cell membrane and the spike protein, allowing the viral genetic material to be replicated within the human host cell. ${ }^{9}$

In December 2020, the United States Food and Drug Administration issued emergency use authorization (EUA) for mRNA vaccines developed by Pfizer-BioNTech and Moderna, followed quickly by EUAs for the adenovirus (viral vector) vaccines developed by Johnson \& Johnson and Astra-Zeneca. ${ }^{10}$ These vaccines produced multiple antibodies to various regions of the SARS-CoV-2 spike protein including antibodies that targeted the RBD of the Spike protein, thereby preventing the virus from anchoring to the human ACE2 receptor and preventing host cell entry. ${ }^{11-12}$ The vaccines were extremely effective; reducing hospitalizations and deaths among the vaccinated. ${ }^{13-14}$

Table 1. Summary and timeline of SARS-COV-2 Mutational Variants with a particular focus on the Spike RBD. ${ }^{4,15-16}$ The sequence of the Wuhan Hu-1 Spike RBD ${ }^{17}$ against which all current vaccines are prepared is shown in the Figure S1.

\begin{tabular}{cccc}
\hline $\begin{array}{c}\text { WHO } \\
\text { Designation }\end{array}$ & Detected & S-RBD Mutation(s) & Comments \\
\hline alpha & Sept 2020 & N501Y & increased transmission $^{18}$
\end{tabular}




\begin{tabular}{|c|c|c|c|}
\hline beta & Oct 2020 & K417N, E484K, N501Y & $\begin{array}{l}\text { Binds ACE2 receptor } \\
\text { with } 4.62 \text { times greater } \\
\text { affinity than original Hu- } \\
1 \text { spike RBD. }{ }^{8}, 19-20 \\
\text { Increased transmission } \\
\text { rates }^{21}\end{array}$ \\
\hline delta & late 2020 & K417N, L452R, T478K & Increased transmission \\
\hline gamma & Jan 2021 & L452R, T478K & Increased transmission \\
\hline omicron & Nov 2021 & $\begin{array}{l}\text { G339D, S371L, S373P, } \\
\text { S375F, K417N, N440K, } \\
\text { G446S, S477N, T478K, } \\
\text { E484A, Q493K, G496S, } \\
\text { Q498R, N501Y, Y505H }\end{array}$ & $\begin{array}{l}\text { Concerning number }(15) \\
\text { of mutations in the Spike } \\
\text { protein RBD }\end{array}$ \\
\hline
\end{tabular}

The vaccines continued to provide protection from mutated forms of the virus. ${ }^{4}$ Breakthrough infections were known, but hospitalizations and deaths among the vaccinated remained low. In November 2021, a mutant variant was detected in a variety of locations around the world. This mutant, labeled as Omicron by the World Health Organization, contained a much larger number of mutations than had previously been observed in the SARS-CoV-2 virus and initial reports displayed a concerning rate of transmission..$^{22-23}$ 


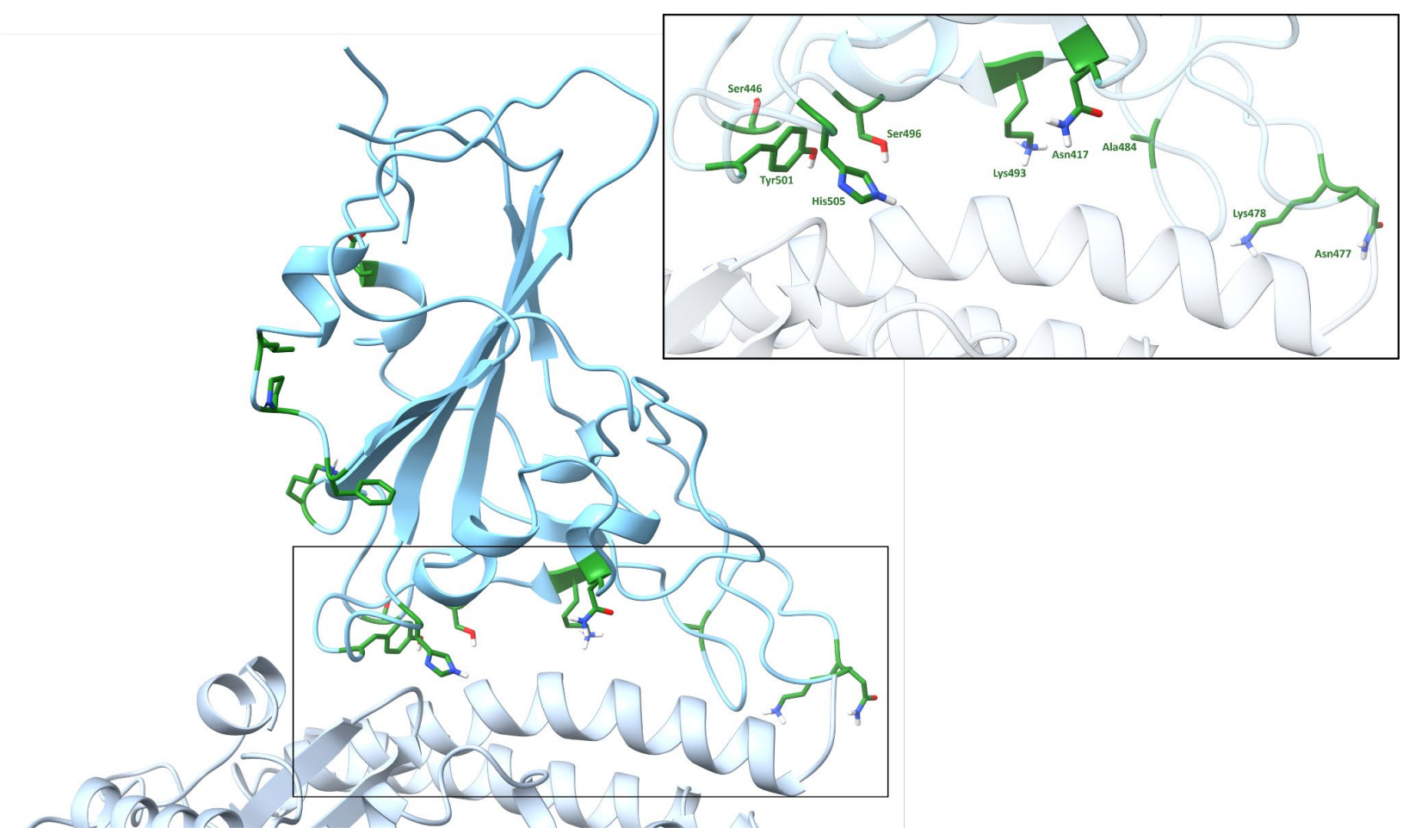

Figure 1. Omicron SARS-CoV-2 RBD - hACE2 interaction. Omicron SARS-CoV-2 RBD is displayed in blue and hACE2 is displayed in a lighter blue. In green are the omicron SARS-CoV2 RBD residue mutations: G339D, S371L, S373P, S375F, K417N, N440K, G446S, S477N, T478K, E484A, Q493K, G496S, Q498R, N501Y, and Y505H. The binding site for the RBD hACE2 interaction and the residues K417N, G446S, S477N, T478K, E484A, Q493K, G496S, $\mathrm{N} 501 \mathrm{Y}$, and $\mathrm{Y} 505 \mathrm{H}$ are shown in the inset.

There is concern that mutations in the RBD region of the spike protein may increase the ability of the spike to bind to the human ACE2 receptor or allow it to evade polyclonal antibody recognition. A number of spike protein residues in the original Wuhan Hu-1 RBD (Lys417; Glu484, Gln493, Gln498, Gly496, Asn501, Tyr505 and Gly446) that were mutated in the omicron variant have previously shown persistent interactions with the hACE2 receptor. ${ }^{8,24}$ Mutations at positions 498 and 501 are particularly worrisome as in-vitro evolution studies suggest that such mutations increase the binding between the spike protein and hACE2 $2{ }^{25}$ Tyr449 may also be an important residue for interaction with $\mathrm{ACE} 2^{24}$ while the $\mathrm{N} 439 \mathrm{~K}$ spike protein variant may increase ACE2 affinity by the formation of a new salt bridge at the RBD-ACE2 interface with Glu329 of hACE2. ${ }^{26}$ 
In this report, we utilize molecular dynamics, structural analysis and MM-GBSA binding estimations to compare the binding properties of the Wuhan Hu-1 and omicron RBD spike protein to the hACE2 receptor. Molecular simulations play a critically important role in understanding the atomistic nature of protein dynamics and proteinligand binding affinities. ${ }^{27-30}$ Since the pandemic began, there have been multiple reports describing the use of molecular dynamics and MM-GBSA to understand SARS-COV-2 behavior. MM-GBSA has been used to estimate hACE2 binding with a.) the original SARS-CoV-2 spike protein RBD, ${ }^{31}$ b.) SARS-CoV and SARS-CoV-2, ${ }^{24,32-33}$ c.) in vitro single point spike mutations, ${ }^{34}$ d.) alpha, kappa and delta mutants, ${ }^{35}$ and e.) RBD hotspot mutations. ${ }^{36}$ MM-GBSA has also been used for an evaluation of the binding affinity between the SARS-CoV-2 spike RBD and the ACE2 receptor from various mammals (human, monkey, hamster, ferret, dog, cat). ${ }^{37}$

In this study, we analyze how the omicron mutations affect the binding of the spike protein to the hACE2 receptor by performing molecular dynamics and binding free energy computations on the wild type (WT) and omicron mutant versions. We find that in spite of the significant number of mutations in the RBD of the spike protein, the binding affinity between the original $\mathrm{Hu}-1$ virus and the omicron variant are similar. We do see structural differences, and these are described in some detail; however, these do not lead to an overall increase in hACE2 affinity.

\section{Methods}

\section{Protein Retrieval and Preparation}

An hACE2 - SARS-CoV-2 RBD crystal structure was obtained from the Protein Data Bank (PDB Code 6LZG) ${ }^{38}$ Chains A (hACE2) and B (SARS-CoV-2 RBD) were selected from 6LZG, and all waters were removed. Schrödinger's Protein Preparation Wizard was used to add missing hydrogen atoms, assign bond orders according to the CCD database, fill missing side chains using Prime, predict side chain protonation states 
using Epik with a pH range of $7 \pm 2$, and optimize H-bonds using PROPKA at a $\mathrm{pH}$ of 7. ${ }^{39,40,41}$ Restrained minimization was then performed using the OPLS3e force field. ${ }^{42}$

\section{Molecular Dynamics Simulations}

Unrestrained molecular dynamics (MD) were performed on the binary complex of SARS-CoV-2 RBD with hACE2 using the GPU-accelerated pmemd code of AMBER $18 .^{43-45}$. The $f f 14$ SB and Glycam06j force fields were used to model the glycoproteins. ${ }^{46,47}$ All models were neutralized with $\mathrm{Na}^{+}$ions and explicitly solvated in a TIP3P unit cell using the program tleap. ${ }^{48}$ Further details describing the MD protocol can be found in the Supplemental Information. Initially, $20100 \mathrm{~ns}$ trajectories were generated, each using different seeds to speed surface coverage. We concatenated the 10 seeds from each of the different spike RBD structures to obtain $1 \mu$ s ensembles for wild type and mutant binary complexes, initiated using the 6LZG experimental structure. We then extended these seeds by another $100 \mathrm{~ns}$ ( $200 \mathrm{~ns}$ total) and produced concatenated 2 $\mu$ s ensembles for the wild type and mutant complexes as well.

\section{Molecular Dynamics Analyses}

Trajectory visualization was conducted using UCSF Chimera and UCSF ChimeraX ${ }^{49,50}$ Using the AmberTools MMPBSA.py package, MM-GBSA binding free energies (calculated for every frame) and pairwise decomposition energies (calculated for frames at a $1 \mathrm{~ns}$ interval) were obtained. ${ }^{51}$ Hydrogen bonding, center-of-mass distance $(\mathrm{COM})$, root-mean-squared deviation (RMSD), root-mean-squared fluctuation (RMSF), secondary structure, backbone atom RMSD-based clustering, and non-hydrogen atom pairwise distance-based clustering analyses were conducted using the AmberTools cpptraj module. ${ }^{43}$ Each clustering method resulted in 10 families per model.

\section{Results and Discussion}

Our overarching goal is to compare the hACE2 binding behavior of the RBD in the Hu-1 spike protein (Wild Type (WT)) relative to the mutated omicron RBD spike protein. To that end, we built an omicron spike RBD by making in silico mutations of the 
RBD in the Hu-1 spike-ACE2 experimental structure (6LZG). Our approach assumes that the 15 mutations present in the omicron variant are not changing significantly the conformation of the spike RBD, and that atomic relaxation via local minimization is enough to stabilize our in silico mutated structure. Using the initial Hu-1 structure (6LZG), as well as the computationally mutated 6LZG structure, we first performed 100 ns of molecular dynamics simulation using 10 different, randomly selected, initial seeds. This generated $1 \mu$ s ensembles for each molecular system. MM-GBSA binding free energy analysis (Table 2) over each $1 \mu$ s ensemble suggests similar hACE2 binding behavior between the WT and Omicron RBD. We then extended these 10 seeds by another $100 \mathrm{~ns}$ (for a total of $200 \mathrm{~ns}$ per each seed) and conducted this same analysis on the resultant $2 \mu$ s ensembles. No significant differences in MM-GBSA binding free energy from the $1 \mu$ s ensembles are reported (Table 2). As such, all further analyses were conducted on the $1 \mu$ s ensembles for computational efficiency.

Table 2. MM-GBSA Binding Energy ( $\mathrm{kcal} / \mathrm{mol})$ of each 1 and $2 \mu$ s ensemble of WT and mutant SARS-CoV-2 RBD with hACE2.

\begin{tabular}{|c|c|c|c|c|}
\hline \multirow{2}{*}{} & \multicolumn{2}{|c|}{$1 \mu \mathrm{s}$} & \multicolumn{2}{c|}{$2 \mu \mathrm{s}$} \\
\cline { 2 - 5 } & $\begin{array}{c}\text { MM-GBSA Avg. } \\
(\mathrm{kcal} / \mathrm{mol})\end{array}$ & $\begin{array}{c}\text { Std. Dev. } \\
(\mathrm{kcal} / \mathrm{mol})\end{array}$ & $\begin{array}{c}\text { MM-GBSA Avg. } \\
(\mathrm{kcal} / \mathrm{mol})\end{array}$ & $\begin{array}{c}\text { Std. Dev. } \\
(\mathrm{kcal} / \mathrm{mol})\end{array}$ \\
\hline WT & -28.45 & 11.33 & -29.69 & 10.61 \\
\hline Omicron & -25.61 & 7.57 & -26.67 & 7.31 \\
\hline
\end{tabular}

To assess conformational dynamics and simulation convergence, we computed the RMSD of each ensemble conformation, relative to the corresponding initial structure. Apart from a brief increase in RMSD between 20 and 40 ns of WT seed 1 (Figure S3) and increased RMSD from 30 ns onwards in seed 5 of the omicron mutant (Figure S3), RMSD analysis shows that both the WT and omicron mutant complexes do not sample conformations significantly different from the initial structure, and are relatively well converged across each seed, with RMSD values ranging from 2 to $3.5 \AA$. There are no significantly notable differences in the RMSD behavior of the WT and omicron mutant. 
This suggests thorough sampling of the dynamics of each complex and that the ensembles we are using to estimate binding free energy are conformationally converged.

We also performed root mean square fluctuation (RMSF) per residue analysis on each $1 \mu$ s ensemble (Figure 2). This analysis indicates that the fluctuations of individual residues are also well conserved between seeds. Comparison of the RMSF trajectories for the WT and omicron mutant suggest relatively similar residue movements with the only area of marked difference occurring between spike residues 384 to 390 . This region does not contain any omicron mutations, and is relatively distant from spike residues responsible for hACE2 binding, but is notably 10 residues away from the proline point mutation S373P. Secondary structure analysis indicates that the decrease in RMSF for omicron residues 384 - 390 results from the formation of a 3-10 helix involving residues L387, N388, and D389. Within the omicron ensemble, this helix occurs with a frequency of $69.26 \%$ while the corresponding region of the WT complex shows helical secondary structure in only $4.25 \%$ of the RBD ensemble (Figure 3).
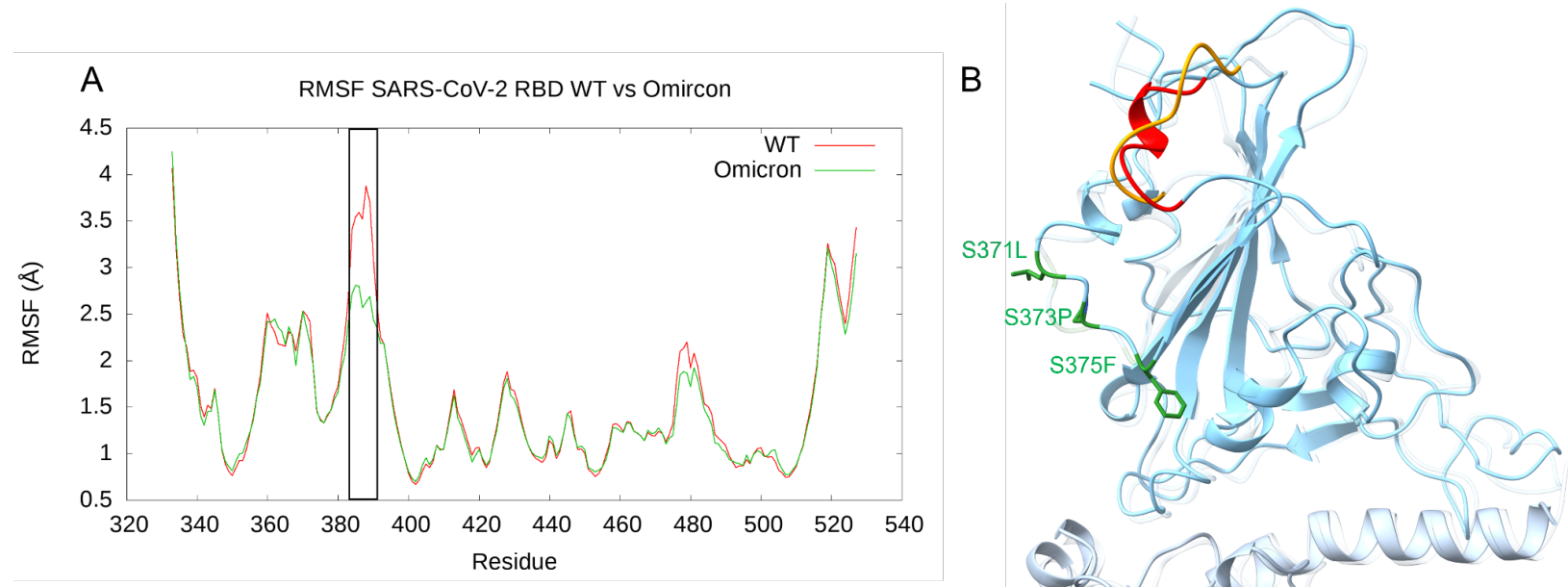

Figure 2. Wild Type and Omicron SARS-CoV-2 RBD and hACE2 Root Mean Square Fluctuation Graphs. [A] RMSF graph of the WT and Omicron RBD concatenated $1 \mu \mathrm{s}$ trajectories. Notably, a difference in RMSF in RBD residues 384 - 390 is highlighted in the black box. [B] The Omicron RBD with the WT RBD superimposed. The most prevalent average structures of both models are shown. The Omicron RBD is displayed in blue and hACE2 in lighter blue, while the WT RBB and hACE2 are displayed in the same colors with a transparency effect applied. Amino acids highlighted in green are mutated residues that are notably close to 
the residues highlighted in red, which are responsible for the increase in omicron mutant RMSF depicted in A. In orange are WT RBD residues 384 - 390.
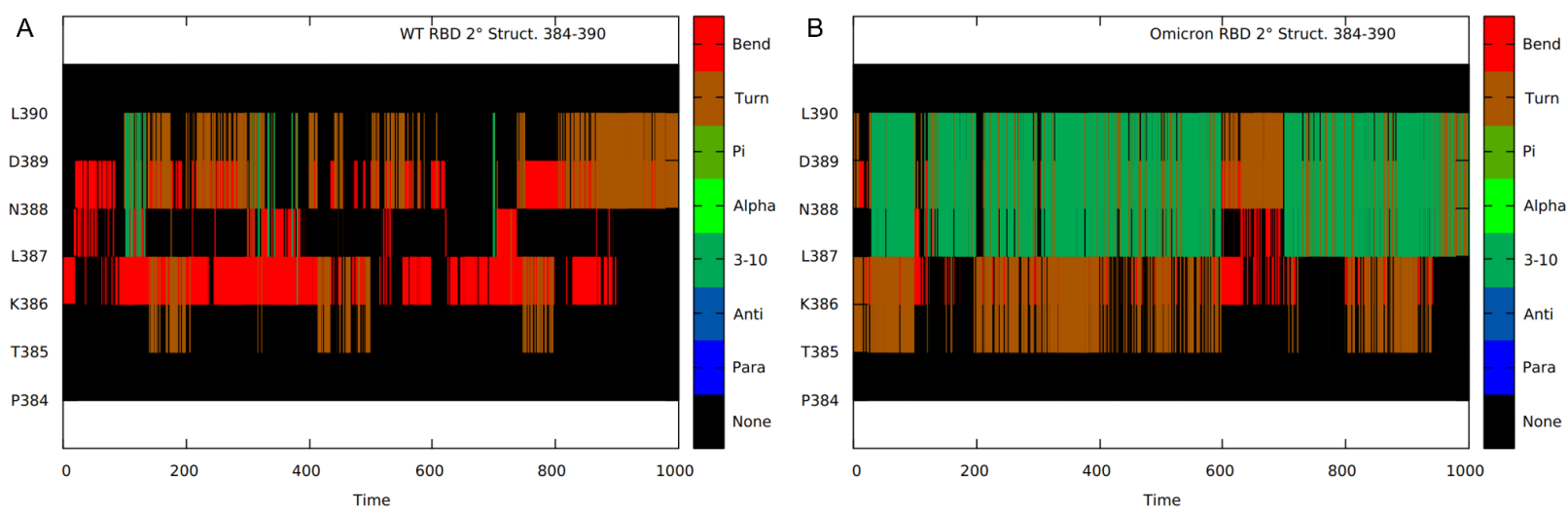

Figure 3. Secondary Structure of Residues 384 - 390. [A] WT secondary structure. [B] Omicron secondary structure.

Given the similarities in RMSD, RMSF, and MM-GBSA binding free energies, we can conclude that the 15 point mutations in the RBD of the omicron variant do not increase the binding affinity for hACE2. This suggests that any noted increase in infectivity of the Omicron mutant over the WT is likely not due to an enhanced interaction between the RBD and hACE2.

As previously reported in this journal, molecular dynamics was used by Ali and Vijayan to characterize residues responsible for the affinity between the WT RBD of the spike protein and hACE2. ${ }^{24}$ To better understand the RBD - hACE2 interactions and the relative proximity of each monomer, we used the 15 residue contacts of Ali and Vijayan (listed in Table S1) to perform an averaged center of mass distance analysis between WT and Omicron RBD and hACE2. Our data suggests few differences between WT and Omicron interactions. Only the RBD Q493K - hACE2 K31 contact shows a significant increase in both $\alpha$ carbon $(8.53 \pm 0.49 \AA \mathrm{WT} ; 9.32 \pm 0.51 \AA$ mutant $)$ and end-to-end distances $(4.00 \pm 0.99 \AA \mathrm{WT} ; 6.88 \pm 1.11 \AA$ mutant $)$, while the RBD K417N - hACE2 D30 contact shows a significant all-atom $(8.29 \pm 0.68 \AA$ WT; $9.75 \pm 0.74 \AA$ mutant $)$ and end-to-end distance increase $(4.04 \pm 1.30 \AA \mathrm{WT} ; 7.85 \pm 1.30 \AA$ mutant) (Table S2). These distance increases corresponding with the Q493K and K417N mutations are 
visualized in the graphs of Table S3. These COM increases make sense as the first case (RBD Q493K - hACE2 K31) a neutral residue (Q493) in the WT interacting with a positively charged residue (K31) is replaced with a positively charged residue (493K) leading to an unfavorable electrostatically repulsive interaction. In the second case (RBD K417N - hACE2 D30), a positively charged residue in the WT (K417) interacting with a negatively charged hACE2 residue (D30) is replaced in the mutant with a neutral residue $(417 \mathrm{~N})$ reducing what was an electrostatically favorable interaction. We also see that, within the large standard deviations shown for the WT contacts RBD Q498R - hACE2 D38 and RBD Q498R - hACE2 K353, the end-to-end distances increase in the mutant $(6.88 \pm 2.38 \AA$ WT; $8.21 \pm 1.38 \AA$ mutant, and $5.51 \pm 2.25 \AA$ WT; $8.73 \pm 1.29 \AA$ mutant, respectively) while the end-to-end distance for RBD K417N - hACE2 H34 decreases in the omicron mutant $(7.93 \pm 1.78 \AA \mathrm{WT} ; 6.66 \pm 0.87 \AA$ mutant $)$. In the case of Q493K and Q498R, the mutations replace a neutral glutamine residue with a charged lysine or arginine, whereas for $\mathrm{K} 417 \mathrm{~N}$, the mutation replaces a charged lysine with an uncharged asparagine. This further suggests that the omicron mutations produce both increased favorable and unfavorable interactions relative to the WT. The graphs in Table S3 suggest that a $\sim 4 \AA$ end-to-end distance for contacts between RBD Q498R - hACE2 D38, and RBD Q498R - hACE2 K353, rarely occur with Omicron. Notably, despite not being subject to mutation, the RDB Y449 - hACE2 D38 interaction also shows an increased average distance in the mutant $(4.50 \pm 2.53 \AA \mathrm{WT} ; 6.85 \pm 1.58 \AA$ mutant $)$ and little occurrence of $\mathrm{a} \sim 4 \AA$ end-to-end distance contact in the Omicron trajectory.

Pairwise decomposition analysis is largely consistent with our MM-GBSA results. A simple summation of each favorable interacting residue pair (Table 3) yields total energies of -54.68 and $-59.63 \mathrm{kcal} / \mathrm{mol}$ for the WT and Omicron models respectively. Likewise, a summation of all pairwise interactions (both favorable and unfavorable) yields total energies of -117.35 and $-110.83 \mathrm{kcal} / \mathrm{mol}$, for the WT and mutant, respectively. This further suggests little difference in hACE2 binding affinity, within the limits of the molecular mechanics energy model, for the WT and Omicron RBD. Our data 
suggests that favorable WT interactions lost as a result of mutation appear to be offset by roughly equally favorable new interactions in the mutant, and vice versa.

Table 3. WT and Omicron SARS-CoV-2 RBD - hACE2 Pairwise Decomposition Energies. Pairwise decomposition energies that are more favorable (less) than $-2.00 \mathrm{kcal} / \mathrm{mol}$ are listed. The pairwise decomposition energies are calculated from the full $1 \mu$ s ensemble and are reported with the corresponding SARS-CoV-2 RBD and hACE2 residues. Spike mutant residues are shown in red.

\begin{tabular}{|c|c|c|c|c|c|}
\hline $\begin{array}{c}\text { SARS-CoV-2 } \\
\text { RBD WT } \\
\text { Residue }\end{array}$ & hACE2 & $\begin{array}{c}\text { Pairwise Decomp. } \\
\text { (avg. } \pm \text { std. dev. }) \\
\text { (kcal/mol) }\end{array}$ & $\begin{array}{c}\text { RARD Omicron } \\
\text { Residue }\end{array}$ & $\begin{array}{c}\text { hACE2 } \\
\text { Residue }\end{array}$ & $\begin{array}{c}\text { Pairwise } \\
\text { Decomp. (avg. } \pm \\
\text { std. dev. } \\
\text { (kcal/mol) }\end{array}$ \\
\hline Lys417 & Asp30 & $-5.92 \pm 3.34$ & Lys493 & Glu35 & $-10.25 \pm 3.21$ \\
\hline Thr500 & Asp355 & $-5.14 \pm 2.38$ & Lys493 & Asp38 & $-8.09 \pm 3.61$ \\
\hline Tyr505 & Lys353 & $-5.06 \pm 0.54$ & Thr500 & Asp355 & $-6.44 \pm 2.08$ \\
\hline Asn501 & Lys353 & $-5.01 \pm 1.47$ & Tyr501 & Lys353 & $-6.38+1.00$ \\
\hline Gln493 & Glu35 & $-4.84 \pm 1.62$ & His505 & Lys353 & $-4.96 \pm 1.45$ \\
\hline Gln493 & Lys31 & $-4.10 \pm 2.04$ & Asn477 & Ser19 & $-3.37 \pm 2.68$ \\
\hline Tyr449 & Asp38 & $-3.26 \pm 2.17$ & Asn487 & Tyr83 & $-2.98 \pm 0.89$ \\
\hline Gly496 & Lys353 & $-3.07 \pm 1.74$ & Lys493 & His34 & $-2.61 \pm 1.41$ \\
\hline Asn487 & Tyr83 & $-3.02 \pm 0.92$ & Ala475 & Ser19 & $-2.46 \pm 1.54$ \\
\hline Gln498 & Lys353 & $-3.00 \pm 3.33$ & Phe486 & Met82 & $-2.35 \pm 0.79$ \\
\hline
\end{tabular}




\begin{tabular}{|c|c|c|c|c|c|}
\hline Asn487 & Gln24 & $-2.99 \pm 0.90$ & Tyr489 & Lys31 & $-2.16 \pm 0.67$ \\
\hline Tyr505 & Glu37 & $-2.59 \pm 2.37$ & Ser496 & Asp38 & $-2.05 \pm 2.40$ \\
\hline Phe486 & Met82 & $-2.50 \pm 0.81$ & & & \\
\hline Asn501 & Tyr41 & $-2.13 \pm 1.21$ & & & \\
\hline Gln493 & His34 & $-2.05 \pm 1.34$ & & & \\
\hline
\end{tabular}

Several changes in interaction energies occur from the WT to omicron mutant. The Q493K mutation significantly increases binding. In the WT, neutral Gln493 contributes -4.84 and $-4.10 \mathrm{kcal} / \mathrm{mol}$ when bound to hACE2 Glu35 and Lys31, respectively. In the Omicron RBD however, the mutation to a positively charged Lys493 creates very favorable interactions with hACE2 Glu35 (-10.25 kcal $/ \mathrm{mol})$, and a new interaction with hACE2 Asp38 (-8.09 kcal/mol), while the interaction with hACE2 Lys31 is expectedly lost. In the WT, the S477 is not involved in a significant interaction, however in Omicron the S477N mutation creates an interaction with a binding energy contribution of $-3.37 \mathrm{kcal} / \mathrm{mol}$ with hACE2 Ser19. Conversely, one of the strongest WT interactions between RBD Lys417 and hACE2 Asp 30 (-5.92 kcal/mol) is eliminated by the K417N mutation in Omicron. Similarly, the G496S and Q498R mutations result in lost interactions with hACE2 Lys353 (-3.07 and $-3.00 \mathrm{kcal} / \mathrm{mol}$ respectively). Despite not being subjects of mutation, WT interactions RBD Tyr449 - hACE2 Asp38 and RBD Asn487 - hACE2 Gln24 are also diminished in the Omicron model. (Tables 3, S6 - S7) Many of these changes are supported by COM distance analysis. (Tables S2 - S3)

Interactions unaffected or preserved by mutation are also observed. The Q493K mutation does not disrupt the favorable interaction with His34 in the WT. The mutation Y505H does not seem to affect binding. In both the WT and omicron mutant, residue 505 interacts similarly with hACE2 residue Lys353 (WT: RBD Tyr505 - hACE2 Lys 353 $5.06 \mathrm{kcal} / \mathrm{mol}$; Omicron: RBD His505 - hACE2 Lys353 -4.96 kcal/mol), while the 
interaction with Glu37 doesn't change significantly with respect to standard deviation. Similarly, mutation N501Y also does not affect binding. In both the WT and mutant, residue 501 interacts similarly with hACE2 residue Lys353 ((WT: RBD Asn501 hACE2 Lys353 -5.01 kcal/mol; Omicron: RBD Tyr501 - hACE2 Lys353 -6.38 kcal/mol) and Tyr41 ((WT: RBD Asn501 - hACE2 Tyr 41 -2.13 kcal/mol; Omicron: RBD Tyr501 - hACE2 Lys353 - $1.42 \mathrm{kcal} / \mathrm{mol}$ ). Interactions not subject to mutation, RBD Thr500 hACE2 Asp355, RBD Asn487 - hACE2 Tyr83, and RBD Ala475 - hACE2 Ser19, are unchanged between the WT and Omicron models. (Table 3, S6 - S7)

Based on hydrogen bonding analysis, there is a decrease in significant (above 5\%) hydrogen bonding interactions between mutated RBD residues and hACE2 residues compared to WT RBD - hACE2 interactions (Tables 4 and 5). One interaction that is present in both WT and omicron is the hydrogen bond with the residue Q493K to the hACE2 residue Glu35 (WT: $68.16 \%,-4.84 \pm 1.62$ and Omicron: $66.05 \%,-10.25 \pm 3.21$ ). An additional 7 hydrogen bonding interactions are maintained between RBD and hACE2 residues for WT and Omicron (Table 4). Notably, these interactions are between nonmutated RBD residues for both WT and Omicron. The interaction RBD Thr500 - hACE2 Tyr41 appears to be significant for both WT and Omicron but there is a notable difference in hydrogen bonding occurrence (WT: $29.74 \%$ and Omicron: 10.26\%). Also, Table 4 shows that the interactions RBD Tyr449 - hACE2 Asp38, RBD Tyr489 - hACE2 Tyr83, and RBD Tyr495 - hACE2 Lys353 are significant hydrogen bonding interactions for the WT but are not significant interactions for omicron. 
Table 4. WT and Omicron SARS-CoV-2 RBD - hACE2 Hydrogen Bonding Occurrences. Individual hydrogen bonding percentages (Table S4 - S5) were combined for interactions between the same residues and rotationally equivalent atoms on each residue. For example, the hydrogen bonding interactions between RBD Lys 493 and ACE2 Asp 38 (62.53\%) are comprised of individual interactions between OD1 and OD2 with N-H1, N-H2 and N-H3 (Table S5 rows 10 (11.66\%); 15 (10.65\%); $18(10.30 \%) ; 20(10.14 \%) 21(10.05 \%)$ and $22(9.73 \%))$. Unless specified, these consist of sidechain - sidechain interactions. Hydrogen bonding percentages that are greater than $5 \%$ are listed. In red are SARS-CoV-2 mutated residues.

\begin{tabular}{|c|c|c|c|c|c|}
\hline $\begin{array}{l}\text { SARS-CoV- } \\
2 \text { RBD WT } \\
\text { Residue }\end{array}$ & hACE2 Residue & $\begin{array}{c}\text { H-Bond \% } \\
\text { Occur. } \\
\text { (avg..) }\end{array}$ & $\begin{array}{c}\text { SARS-CoV- } \\
2 \text { RBD } \\
\text { Omicron } \\
\text { Residue }\end{array}$ & hACE2 Residue & $\begin{array}{c}\text { H-Bond \% } \\
\text { Occur. } \\
\text { (avg..) }\end{array}$ \\
\hline \multirow[b]{2}{*}{ Asn487 } & Tyr83 & 83.27 & \multirow[b]{2}{*}{ Asn487 } & Tyr83 & 72.75 \\
\hline & Gln24 & 23.27 & & Gln24 & 14.15 \\
\hline Gly502 & Lys353 & 77.58 & \multirow[b]{2}{*}{ Thr500 } & Asp355 & 67.49 \\
\hline \multirow[b]{3}{*}{ Gln493 } & Glu35 & 68.07 & & Tyr41 & 10.26 \\
\hline & His34 & 7.66 & \multirow[b]{2}{*}{ Lys493 } & Glu35 & 66.05 \\
\hline & Lys31 & 42.66 & & Asp38 & 62.53 \\
\hline Tyr449 & Asp38 & 62.55 & Gly502 & Lys353 & 57.00 \\
\hline \multirow[t]{2}{*}{ Lys417 } & Asp30 & 62.26 & \multirow{3}{*}{ Ala475 } & Ser19 Sidechain & 38.27 \\
\hline & & & & Ser19 Backbone & 16.28 \\
\hline \multirow[b]{2}{*}{ Thr500 } & Asp355 & 58.69 & & Gln24 & 5.28 \\
\hline & Tyr41 & 29.75 & Ser496 & Asp38 & 38.20 \\
\hline \multirow{3}{*}{ Tyr505 } & Glu37 & 49.41 & Asn477 & Ser19 Sidechain & 28.22 \\
\hline & & & & Ser19 Backbone & 11.42 \\
\hline & Ala386 & 7.21 & Tyr453 & His34 & 19.68 \\
\hline \multirow[b]{2}{*}{ Gln498 } & Lys353 & 35.95 & Arg498 & Gln42 & 12.77 \\
\hline & Asp38 & 24.17 & & & \\
\hline \multirow{3}{*}{ Ala475 } & Ser19 Sidechain & 31.34 & & & \\
\hline & Ser19 Backbone & 5.85 & & & \\
\hline & Gln24 & 7.60 & & & \\
\hline Gly496 & Lys353 & 30.70 & & & \\
\hline Tyr453 & His34 & 24.79 & & & \\
\hline
\end{tabular}




\begin{tabular}{|c|c|c|l|l|l|l|}
\hline Tyr489 & Tyr83 & 8.29 & & & & \\
\hline Tyr495 & Lys353 & 9.32 & & & \\
\cline { 1 - 2 } \cline { 5 - 6 } Gly446 & Gln42 & 8.17 & & & \\
\hline
\end{tabular}

In Tables 3 and 4 we have presented pairwise decomposition and hydrogen bonding analysis of the WT and omicron $1 \mu$ s ensembles rank ordered according to favorability and percent occurrence, respectively. In Table 5 we present pairwise and hydrogen-bonding data for all RBD mutated residues regardless of their values. In addition, we specify whether the hydrogen bonding occurs between side chain (S) or backbone (B) atoms. Significant hydrogen bonding interactions of the WT RBD with hACE2 (RBD Lys417 - hACE2 Asp30, RBD Gly446 - hACE2 Gln42, RBD Gln493 hACE2 Lys31, RBD Gly496 - hACE2 Lys353, RBD Gln498 - hACE2 Asp38, RBD Gln498 - hACE2 Lys353, RBD Tyr505 - hACE2 Glu37, and RBD Tyr505 - hACE2 Ala386) appear to be destroyed or diminished upon residue mutation in the omicron variant. Notably, such residue mutations do not seem to introduce many new hydrogen bonding interactions, and as such, the data in Table 5 suggests that, relative to WT, omicron mutations reduce hydrogen bonding occurrences more than they increase it.

Additionally, the mutated RBD residues Asn477, Lys493, Ser496, and Arg498 participate in significant hydrogen bonding interactions: RBD Asn477 - hACE2 Ser19, RBD Lys493 - hACE2 Asp38, RBD Ser496 - hACE2 Asp38, and RBD Arg498 hACE2 Gln42. The previously mentioned interactions are not significant for the binding of the WT RBD to hACE2 for the equivalent WT RBD residues. However, the WT interaction RBD Gly496 - hACE2 Asp38 and omicron interaction RBD Ser496 - hACE2 Asp38, unlike the interactions previously mentioned, both have relatively high pairwise decomposition values (WT: $-0.86 \pm 0.85 \mathrm{kcal} / \mathrm{mol}$ and Omicron: $-2.05 \pm 2.40 \mathrm{kcal} / \mathrm{mol}$ ). The omicron hydrogen bonding interactions RBD Ser496 - hACE2 Lys353, RBD Arg498 - hACE3 Asp38, and RBD His505 - hACE2 Glu37, appear to have low hydrogen bonding occurrences compared to the equivalent WT interactions (with 
omicron percent occurrences less than 5\%); however, the pairwise decomposition values of these interactions are significant (Table 5).

Table 5. A comparison of the hydrogen bonding and pairwise decomposition energies for all SARS-CoV-2 RBD mutations. For Omicron and WT each residue is listed with the corresponding hydrogen bonding hACE2 residue(s) and the pairwise decomposition energy for the RBD - hACE2 interaction. All percent occurrences are calculations from the $1 \mu$ s ensemble. Shown in bold are the most significant interactions. [A] The RBD - hACE2 interaction type is indicated. S corresponds to the side chain and B corresponds to backbone, with the first letter representing that of the RBD and the second representing hACE2. The interaction is indicated to distinguish the hydrogen bond percent occurrence listed.

\begin{tabular}{|c|c|c|c|c|c|c|c|c|c|}
\hline $\begin{array}{c}\text { SARS- } \\
\text { CoV-2 } \\
\text { RBD WT } \\
\text { Residue }\end{array}$ & $\begin{array}{l}\text { hACE2 } \\
\text { Residue }\end{array}$ & $\begin{array}{l}\text { Interactio } \\
\text { n Type } \mathrm{e}^{[\mathrm{A}]}\end{array}$ & $\begin{array}{l}\text { H-Bond } \\
\text { \% Occur. } \\
\text { (avg..) }\end{array}$ & $\begin{array}{c}\text { Pairwise } \\
\text { Decomp. } \\
\text { (avg. } \pm \text { std. } \\
\text { dev.) } \\
\text { (kcal/mol) }\end{array}$ & $\begin{array}{c}\text { SARS- } \\
\text { CoV-2 } \\
\text { RBD } \\
\text { Mutant } \\
\text { Residue }\end{array}$ & $\begin{array}{l}\text { hACE2 } \\
\text { Residue }\end{array}$ & $\begin{array}{c}\text { Interac } \\
\text { tion } \\
\text { Type }^{[\mathrm{A}]}\end{array}$ & $\begin{array}{c}\text { H-Bond } \\
\% \\
\text { Occur. } \\
\text { (avg... }^{[\mathrm{D}}\end{array}$ & $\begin{array}{c}\text { Pairwise } \\
\text { Decomp. } \\
\text { (avg. } \pm \\
\text { std. dev.) } \\
\text { (kcal/mol } \\
\text { ) }\end{array}$ \\
\hline Gly339 & - & - & - & - & Asp339 & - & - & - & - \\
\hline Ser371 & - & - & - & - & Leu371 & - & - & - & - \\
\hline Ser373 & - & - & - & - & Pro373 & - & - & - & - \\
\hline Ser375 & - & - & - & - & Phe375 & - & - & - & - \\
\hline \multirow[t]{2}{*}{ Lys417 } & Asp30 & $\begin{array}{l}\text { S-S } \\
\text { S-S } \\
\text { S-B }\end{array}$ & $\begin{array}{c}37.05 \\
25.21 \\
0.01\end{array}$ & $-5.92 \pm 3.34$ & \multirow[t]{2}{*}{ Asn417 } & Asp30 & S-S & 0.06 & $\begin{array}{c}-0.12 \pm \\
0.27\end{array}$ \\
\hline & $\begin{array}{l}\text { NAG - } \\
\text { Asn90 }\end{array}$ & S-B & 0.06 & $-0.002 \pm 0.18$ & & His34 & S-S & 0.03 & $\begin{array}{c}-0.32 \pm \\
0.25\end{array}$ \\
\hline \multirow[b]{2}{*}{ Asn440 } & \multirow{2}{*}{ - } & \multirow{2}{*}{ - } & \multirow{2}{*}{ - } & \multirow{2}{*}{ - } & & Gln325 & S-S & 0.02 & $\begin{array}{c}-0.015 \pm \\
0.028\end{array}$ \\
\hline & & & & & Lys440 & Glu329 & S-S & 0.01 & $\begin{array}{l}-0.075 \\
\pm 0.092\end{array}$ \\
\hline \multirow{3}{*}{ Gly446 } & GIn42 & S-B & 8.68 & $-0.66 \pm 0.92$ & \multirow[b]{2}{*}{ Ser446 } & $\begin{array}{l}\text { Gln42 } \\
\text { Gln42 }\end{array}$ & $\begin{array}{l}\text { S-S } \\
\text { B-S }\end{array}$ & $\begin{array}{l}0.02 \\
0.01\end{array}$ & $\begin{array}{c}-0.11 \pm \\
0.16\end{array}$ \\
\hline & Tyr41 & $\begin{array}{l}\text { B-S } \\
\text { B-S }\end{array}$ & $\begin{array}{l}0.18 \\
0.01\end{array}$ & $-0.17 \pm 0.01$ & & - & - & - & - \\
\hline & Ser19 & $\begin{array}{l}\text { S-B } \\
\text { S-B } \\
\text { S-S }\end{array}$ & $\begin{array}{l}1.22 \\
0.11 \\
0.10\end{array}$ & $-0.39 \pm 0.80$ & & Ser19 & $\begin{array}{l}\text { S-B } \\
\text { S-B } \\
\text { S-S }\end{array}$ & $\begin{array}{c}11.42 \\
28.22 \\
0.18\end{array}$ & $\begin{array}{c}-3.37 \pm \\
2.68\end{array}$ \\
\hline
\end{tabular}




\begin{tabular}{|c|c|c|c|c|c|c|c|c|c|}
\hline \multirow{8}{*}{ Ser477 } & & S-B & 0.05 & & \multirow{8}{*}{ Asn477 } & & $\begin{array}{l}\text { S-S } \\
\text { B-S } \\
\text { S-B }\end{array}$ & $\begin{array}{l}0.06 \\
0.02 \\
0.01\end{array}$ & \\
\hline & \multirow{5}{*}{$\mathrm{G} \ln 24$} & S-S & 0.93 & \multirow{5}{*}{$-0.40 \pm 0.53$} & & \multirow{5}{*}{$\mathrm{G} \ln 24$} & S-S & 2.30 & \multirow{5}{*}{$\begin{array}{c}-0.80 \pm \\
0.76\end{array}$} \\
\hline & & B-S & 0.14 & & & & S-S & 0.08 & \\
\hline & & B-S & 0.09 & & & & B-S & 0.07 & \\
\hline & & S-S & 0.06 & & & & & & \\
\hline & & B-S & 0.02 & & & & & & \\
\hline & \multirow[t]{2}{*}{ Thr20 } & B-S & 0.32 & \multirow[t]{2}{*}{$-0.09 \pm 0.34$} & & \multirow[t]{2}{*}{ Thr20 } & S-S & 0.47 & \multirow{2}{*}{$\begin{array}{c}-0.13 \pm \\
0.38\end{array}$} \\
\hline & & S-S & 0.09 & & & & S-S & 0.13 & \\
\hline \multirow{5}{*}{ Thr478 } & & S-S & 1.68 & & \multirow{5}{*}{ Lys478 } & \multirow{5}{*}{-} & \multirow{5}{*}{ - } & \multirow{5}{*}{-} & \multirow{5}{*}{ - } \\
\hline & Gln24 & B-S & 0.55 & $-0.25 \pm 0.70$ & & & & & \\
\hline & & S-S & 0.16 & & & & & & \\
\hline & Ser19 & S-B & 0.04 & $-0.03 \pm 0.18$ & & & & & \\
\hline & & S-S & 0.01 & & & & & & \\
\hline Glu484 & Lys31 & S-S & 1.04 & $-0.65 \pm 1.26$ & Ala484 & - & - & - & - \\
\hline \multirow{8}{*}{ Gln493 } & & & & & \multirow{8}{*}{ Lys493 } & Glu35 & S-S & 66.05 & $\begin{array}{r}-10.25 \pm \\
3.21\end{array}$ \\
\hline & & S-B & 0.01 & & & & & & \\
\hline & Asp38 & S-S & 0.06 & $-0.27 \pm 0.31$ & & Asp38 & S-S & 62.53 & $\begin{array}{c}-8.09 \pm \\
3.61\end{array}$ \\
\hline & His34 & S-S & 4.42 & & & His34 & S-B & 3.98 & $-2.61 \pm$ \\
\hline & & S-B & 3.24 & $-2.05 \pm 1.34$ & & & S-S & 0.21 & \\
\hline & Lys31 & S-S & 42.66 & $-4.10 \pm 2.04$ & & Lys31 & S-B & 0.01 & $0.36 \pm$ \\
\hline & & S-B & 0.06 & & & & & & \\
\hline & - & - & - & - & & Glu37 & S-S & 0.14 & $\begin{array}{c}-0.09 \pm \\
0.58\end{array}$ \\
\hline \multirow{5}{*}{ Gly496 } & Asp38 & B-S & 0.42 & $-0.86 \pm 0.85$ & \multirow[b]{2}{*}{ Ser496 } & Asp38 & S-S & 38.20 & $\begin{array}{r}-2.05 \pm \\
2.40\end{array}$ \\
\hline & Lys353 & B-S & 30.70 & $-3.07 \pm 1.74$ & & Lys353 & S-S & 2.18 & $\begin{array}{c}-1.86 \pm \\
1.36\end{array}$ \\
\hline & Asp38 & S-S & 25.34 & $-1.84 \pm 2.41$ & & \multirow{3}{*}{ Asp38 } & S-S & 1.14 & \multirow{3}{*}{$\begin{array}{c}-0.71 \pm \\
1.54\end{array}$} \\
\hline & & S-B & 0.01 & & & & S-S & 0.26 & \\
\hline & & & & & & & S-B & 0.05 & \\
\hline
\end{tabular}




\begin{tabular}{|c|c|c|c|c|c|c|c|c|c|}
\hline \multirow{4}{*}{ Gln498 } & Gln42 & $\begin{array}{l}\text { S-S } \\
\text { S-S } \\
\text { S-S }\end{array}$ & $\begin{array}{l}2.33 \\
2.94 \\
0.51\end{array}$ & $-0.41 \pm 1.03$ & \multirow{4}{*}{ Arg498 } & Gln42 & $\begin{array}{l}\text { S-S } \\
\text { S-S } \\
\text { S-S }\end{array}$ & $\begin{array}{l}12.77 \\
0.04 \\
0.02\end{array}$ & $\begin{array}{c}-1.52 \pm \\
1.93\end{array}$ \\
\hline & Tyr41 & $\begin{array}{l}\text { S-S } \\
\text { S-S }\end{array}$ & $\begin{array}{l}0.21 \\
0.08\end{array}$ & $-1.97 \pm 0.64$ & & Tyr41 & S-S & 0.12 & $\begin{array}{c}-2.76 \pm \\
0.70\end{array}$ \\
\hline & Lys353 & S-S & 37.05 & $-3.00 \pm 3.33$ & & - & - & - & - \\
\hline & Asp355 & S-S & 0.06 & $\begin{array}{c}-0.003 \pm \\
0.001\end{array}$ & & & & & \\
\hline \multirow{4}{*}{ Asn501 } & Gln325 & B-S & 0.02 & $-0.01 \pm 0.12$ & \multirow{4}{*}{ Tyr501 } & Gln325 & B-S & 4.95 & $\begin{array}{l}-0.32 \pm \\
1.05\end{array}$ \\
\hline & Lys353 & $\begin{array}{l}\text { S-S } \\
\text { S-B }\end{array}$ & $\begin{array}{l}1.37 \\
0.14\end{array}$ & $-5.01 \pm 1.47$ & & Asp38 & S-S & 2.29 & $\begin{array}{c}-0.05 \pm \\
0.79\end{array}$ \\
\hline & Tyr41 & $\begin{array}{l}\text { S-S } \\
\text { S-S }\end{array}$ & $\begin{array}{l}1.58 \\
0.40\end{array}$ & $-2.13 \pm 1.21$ & & Lys353 & S-S & 0.60 & $\begin{array}{c}-6.38 \pm \\
1.00\end{array}$ \\
\hline & Asp355 & S-S & 0.03 & $-1.84 \pm 0.60$ & & - & - & - & - \\
\hline \multirow{4}{*}{ Tyr505 } & Glu37 & S-S & 49.41 & $-2.59 \pm 2.37$ & \multirow{4}{*}{ His505 } & Glu37 & S-S & 3.30 & $\begin{array}{c}-0.62 \pm \\
1.18\end{array}$ \\
\hline & Ala386 & S-B & 7.21 & $-\mathbf{- 0 . 4 3} \pm \mathbf{0 . 6 8}$ & & Ala386 & S-B & 0.25 & $\begin{array}{c}-0.19 \pm \\
0.23\end{array}$ \\
\hline & Arg393 & S-S & 1.47 & $-1.46 \pm 1.12$ & & Lys353 & S-S & 0.15 & $\begin{array}{c}-4.96 \pm \\
1.45\end{array}$ \\
\hline & Ala387 & S-B & 0.02 & $-0.13 \pm 0.28$ & & - & - & - & - \\
\hline
\end{tabular}

Overall, MM-GBSA estimation, pairwise decomposition energies, hydrogenbonding interactions and center-of-mass distance measurements all suggest that hACE2 binding to the Wuhan-Hu-1 WT and omicron are similar. Some of the point mutations in the Spike-RBD hACE2 interface enhance binding but those enhancements are balanced by mutations that disfavor binding. The mutations that make the most significant affect on binding are shown in Figure 4, where favorable and unfavorable point mutations are shown in green and red, respectively. 


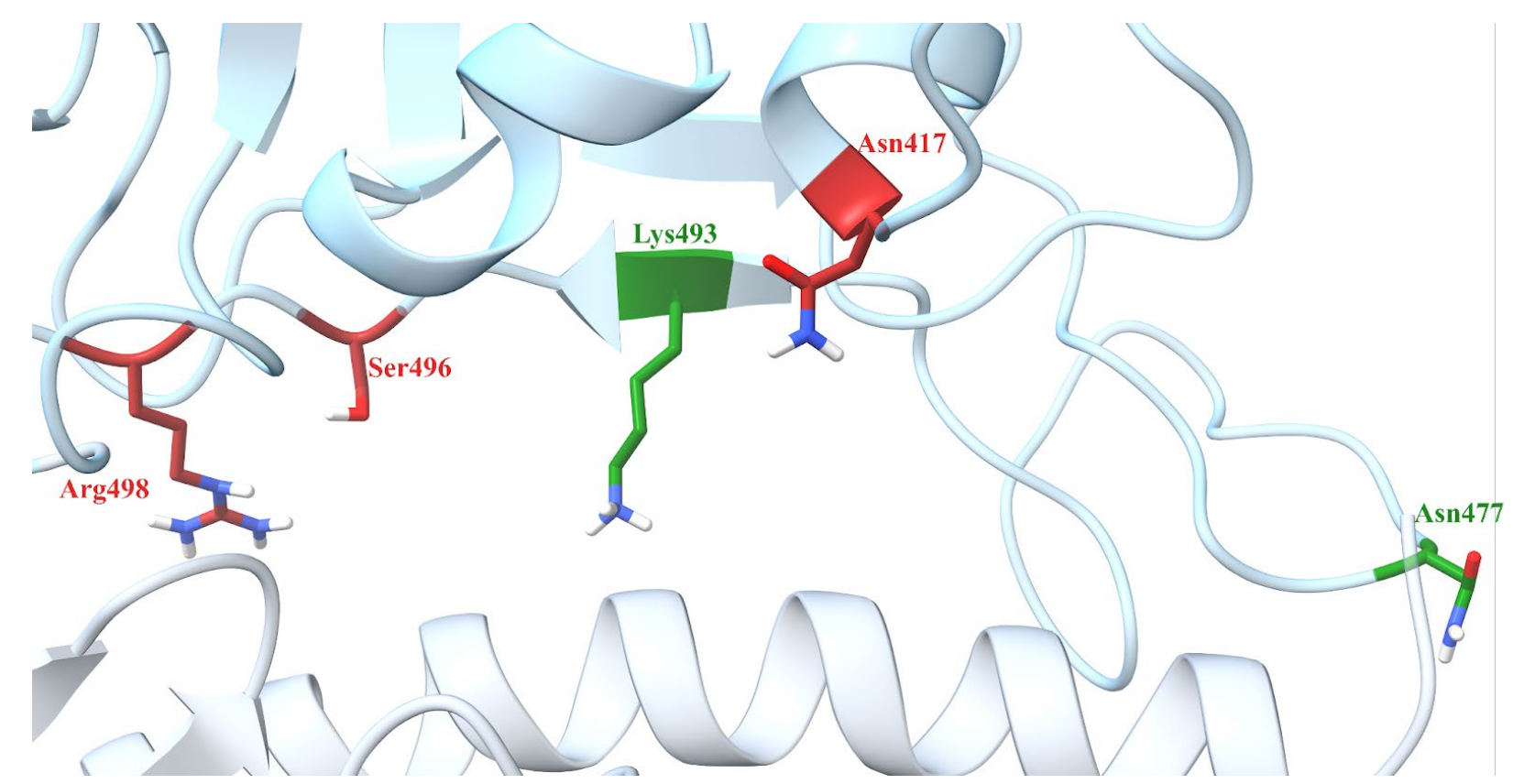

Figure 4. Omicron SARS-CoV-2 RBD - hACE2 interactions. Highlighted are residues that most significantly affect binding based upon hydrogen bonding occurrence and pairwise residue decomposition changes in the WT and omicron variant. Shown in red are mutated residues that display less favorable or less significant interaction. Shown in green are the mutated residues that became more significant for RBD - hACE2 interactions. See Figure S10 for a complete visualization of all residues that play a significant role in WT and omicron binding to hACE2.

\section{Average Structures}

Clustering analysis was conducted using cpptraj to output 10 families for the WT and omicron mutant models. Families were produced using both backbone atom RMSD and non-hydrogen atom pairwise distance clustering. Representative average structures of each family are displayed in Figures 5, S4 - S6. The most populated of the families are displayed in Table 6. Notably, both RMSD and pairwise distance clustering report a single dominant family for the Omicron ensemble with respective occurrences of 77.0 and $80.2 \%$. For the WT, RMSD-based clustering reports four families ranging between $\sim 15$ and $30 \%$ occurrences, while pairwise distance-based clustering reports a single dominant family with an occurrence of $89.6 \%$. Ultimately, RMSD comparisons of representative structures of each family to each other suggests few structural differences (Table 7). These representative structures are freely available at

\section{https://github.com/Parish-Lab/spikeace2.}



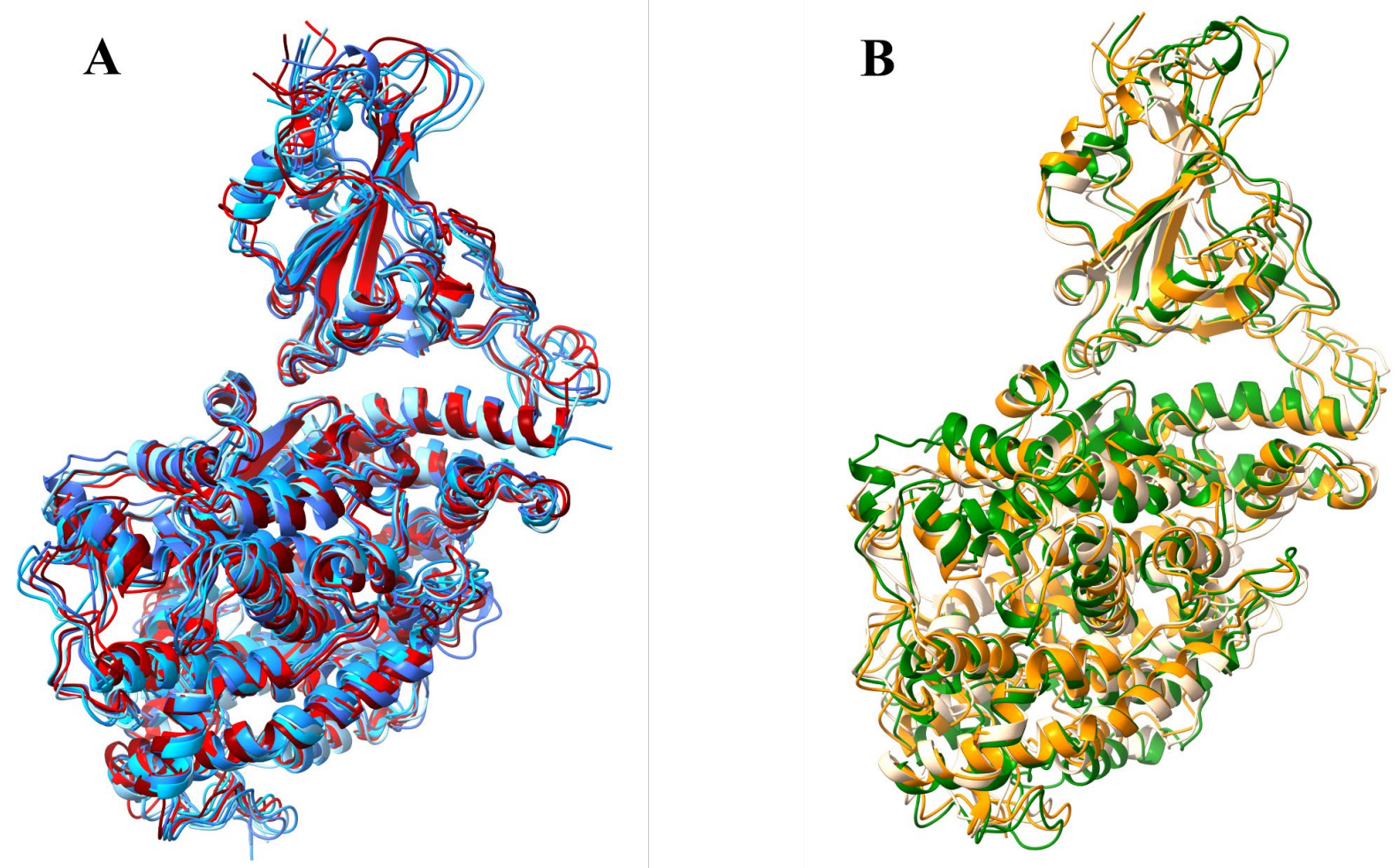

Figure 5. Comparison of the WT and Omicron Cluster Families. [A] Representative structures from WT and omicron clustering using backbone-atom RMSD. The 4 different WT cluster families are represented in shades of blue and the two different omicron cluster families are depicted in shades of red. Individual images of representative structures from each cluster family are shown in Figure S4 and S5. [B] Representative structures from WT and omicron clustering using pairwise distance-based clustering. The WT cluster family is displayed in green and the two different omicron cluster families are depicted in shades of orange. Individual images of the representative structures from each cluster family are shown in Figures S7 and S8.

Table 6. Percent occurrence of WT and Omicron families obtained from clustering analysis. Only families contributing occurrences of greater than $10 \%$ are included.

\begin{tabular}{|c|c|c|c|c|}
\hline \multirow{2}{*}{ Family \# } & \multicolumn{2}{|c|}{ RMSD } & \multicolumn{2}{c|}{ Pairwise Distance } \\
\cline { 2 - 5 } & WT \% & $\begin{array}{c}\text { Omicron } \\
\text { Mutant \% }\end{array}$ & WT\% & $\begin{array}{c}\text { Omicron } \\
\text { Mutant \% }\end{array}$ \\
\hline 1 & 30.4 & 77.0 & 89.6 & 80.2 \\
\hline 2 & 23.3 & 11.0 & - & 11.7 \\
\hline
\end{tabular}




\begin{tabular}{|l|l|l|l|l|}
\hline 3 & 19.2 & - & - & - \\
\hline 4 & 14.8 & - & - & - \\
\hline
\end{tabular}

Table 7. RMSD comparison of representative structures of each clustering family. The RMSD ( $\AA)$ of each family compared with each other is reported. Families labeled with "Pair" were generated from pairwise distance-based clustering, while all other families were generated with RMSD-based clustering.

\begin{tabular}{|c|c|c|c|c|c|c|c|c|c|}
\hline Cluster & WT 1 & WT 2 & WT 3 & WT 4 & O 1 & O 2 & $\begin{array}{l}\text { Pair } \\
\text { WT } 1\end{array}$ & $\begin{array}{l}\text { Pair } \\
\text { O } 1\end{array}$ & $\begin{array}{l}\text { Pair } \\
\text { O } 2\end{array}$ \\
\hline WT 1 & 0 & 2.314 & 1.848 & 2.406 & 2.034 & 2.845 & 2.327 & 2.983 & 2.262 \\
\hline WT 2 & & 0 & 2.168 & 1.926 & 2.169 & 1.819 & 2.767 & 1.982 & 2.048 \\
\hline WT 3 & & & 0 & 2.565 & 2.211 & 2.838 & 2.665 & 2.867 & 2.241 \\
\hline WT 4 & & & & 0 & 2.504 & 1.996 & 2.184 & 2.126 & 2.376 \\
\hline O 1 & & & & & 0 & 2.292 & 2.793 & 2.601 & 1.493 \\
\hline O 2 & & & & & & 0 & 2.737 & 1.902 & 2.045 \\
\hline $\begin{array}{l}\text { Pair } \\
\text { WT } 1\end{array}$ & & & & & & & 0 & 2.937 & 2.953 \\
\hline $\begin{array}{l}\text { Pair } \\
\text { O } 1\end{array}$ & & & & & & & & 0 & 2.265 \\
\hline $\begin{array}{l}\text { Pair } \\
02\end{array}$ & & & & & & & & & 0 \\
\hline
\end{tabular}

\section{Conclusion}

The SARS-CoV-2 virus encodes for a spike protein that contains a receptor binding domain that binds favorably to the ACE2 receptor present on the surface of human cells. This binding allows the virus to enter the cell and to begin host infection. The omicron variant of the SARS-CoV-2 virus possesses 32 point mutations, including 15 in the receptor binding domain of the spike protein. Current vaccines produce 
polyclonal antibodies that target the RBD of the spike protein and prevent the virus from gaining access to human cells. We have utilized molecular dynamics to sample the binding behavior of the wild type and omicron spike protein RBD with hACE2 as well as MM-GBSA to compare their binding affinities for hACE2. We find that the binding affinity between the hACE2 receptor and the WT and omicron mutant spike protein RBD are similar and within the limits of error of the MM-GBSA binding estimation. A detailed analysis of the pairwise decomposition energies, hydrogen-bonding interactions, centerof-mass distance measurements and clustering suggests that while the omicron RBD mutations disrupt some favorable wild type residue interactions, such mutations also produce new favorable interactions. For instance, pairwise analysis shows that the Q493K and S477N mutations significantly increase binding whereas K417N, G496S and Q498R reduce binding. Overall, all analysis suggests that the hACE2 binding favorability is similar between wild type and the omicron variant.

\section{Author Information}

ORCID

Justin Airas: 0000-0001-5045-9926

Camryn Carter: 0000-0002-5952-9297

Carol A. Parish: 0000-0003-2878-3070

\section{Acknowledgements}

This research was supported by funding from the National Science Foundation (Grant CHE-18800014) and the Floyd D. and Elisabeth S. Gottwald Endowment. J.A. and C.C. were recipients of a summer fellowship from the Puryear-Topham-Pierce-Gupton endowment from the Department of Chemistry at the University of Richmond, and from the University of Richmond Integrated and Inclusive Science program, and the Arts and Sciences Undergraduate Research Committee. 


\section{References}

1. Wang, C.; Horby, P. W.; Hayden, F. G.; Gao, G. F., A novel coronavirus outbreak of global health concern. The Lancet 2020, 395 (10223), 470-473.

2. Pascarella, G.; Strumia, A.; Piliego, C.; Bruno, F.; Del Buono, R.; Costa, F.; Scarlata, S.; Agrò, F. E., COVID-19 diagnosis and management: a comprehensive review. J Intern Med 2020, 288 (2), 192-206.

3. Berlin, D. A.; Gulick, R. M.; Martinez, F. J., Severe Covid-19. New England Journal of Medicine 2020, $383(25), 2451-2460$.

4. $\quad$ Harvey, W. T.; Carabelli, A. M.; Jackson, B.; Gupta, R. K.; Thomson, E. C.; Harrison, E. M.; Ludden, C.; Reeve, R.; Rambaut, A.; Peacock, S. J.; Robertson, D. L.; Consortium, C.-G. U., SARS-CoV-2 variants, spike mutations and immune escape. Nature Reviews Microbiology 2021, 19 (7), 409-424.

5. Li, Q.; Wu, J.; Nie, J.; Zhang, L.; Hao, H.; Liu, S.; Zhao, C.; Zhang, Q.; Liu, H.; Nie, L.; Qin, H.; Wang, M.; Lu, Q.; Li, X.; Sun, Q.; Liu, J.; Zhang, L.; Li, X.; Huang, W.; Wang, Y., The Impact of Mutations in SARSCoV-2 Spike on Viral Infectivity and Antigenicity. Cell 2020, 182 (5), 1284-1294.e9.

6. Lauring, A. S.; Hodcroft, E. B., Genetic Variants of SARS-CoV-2-What Do They Mean? JAMA 2021, $325(6), 529-531$.

7. Letko, M.; Marzi, A.; Munster, V., Functional assessment of cell entry and receptor usage for SARS-CoV2 and other lineage B betacoronaviruses. Nature Microbiology 2020, 5 (4), 562-569.

8. Ramanathan, M.; Ferguson, I. D.; Miao, W.; Khavari, P. A., SARS-CoV-2 B.1.1.7 and B.1.351 spike variants bind human ACE2 with increased affinity. The Lancet Infectious Diseases 2021, 21 (8), 1070.

9. $\quad$ Ke, Z.; Oton, J.; Qu, K.; Cortese, M.; Zila, V.; McKeane, L.; Nakane, T.; Zivanov, J.; Neufeldt, C. J.; Cerikan, B.; Lu, J. M.; Peukes, J.; Xiong, X.; Kräusslich, H.-G.; Scheres, S. H. W.; Bartenschlager, R.; Briggs, J. A. G., Structures and distributions of SARS-CoV-2 spike proteins on intact virions. Nature 2020, 588 (7838), 498-502.

10. $\quad$ Guidry, J. P. D.; Laestadius, L. I.; Vraga, E. K.; Miller, C. A.; Perrin, P. B.; Burton, C. W.; Ryan, M.; Fuemmeler, B. F.; Carlyle, K. E., Willingness to get the COVID-19 vaccine with and without emergency use authorization. American Journal of Infection Control 2021, 49 (2), 137-142.

11. Krammer, F., SARS-CoV-2 vaccines in development. Nature 2020, 586 (7830), 516-527.

12. Mascellino, M. T.; Di Timoteo, F.; De Angelis, M.; Oliva, A., Overview of the Main Anti-SARS-CoV-2

Vaccines: Mechanism of Action, Efficacy and Safety. Infection and drug resistance 2021, 14, 3459-3476.

13. Bruxvoort, K. J.; Sy, L. S.; Qian, L.; Ackerson, B. K.; Luo, Y.; Lee, G. S.; Tian, Y.; Florea, A.; Aragones, M.; Tubert, J. E.; Takhar, H. S.; Ku, J. H.; Paila, Y. D.; Talarico, C. A.; Tseng, H. F., Effectiveness of mRNA-1273 against delta, mu, and other emerging variants of SARS-CoV-2: test negative case-control study. BMJ 2021, 375, e068848.

14. Tenforde, M. W.; Self, W. H.; Adams, K.; Gaglani, M.; Ginde, A. A.; McNeal, T.; Ghamande, S.; Douin, D. J.; Talbot, H. K.; Casey, J. D.; Mohr, N. M.; Zepeski, A.; Shapiro, N. I.; Gibbs, K. W.; Files, D. C.; Hager, D. N.; Shehu, A.; Prekker, M. E.; Erickson, H. L.; Exline, M. C.; Gong, M. N.; Mohamed, A.; Henning, D. J.; Steingrub, J. S.; Peltan, I. D.; Brown, S. M.; Martin, E. T.; Monto, A. S.; Khan, A.; Hough, C. L.; Busse, L. W.; ten Lohuis, C. C.; Duggal, A.; Wilson, J. G.; Gordon, A. J.; Qadir, N.; Chang, S. Y.; Mallow, C.; Rivas, C.; Babcock, H. M.; Kwon, J. H.; Halasa, N.; Chappell, J. D.; Lauring, A. S.; Grijalva, C. G.; Rice, T. W.; Jones, I. D.; Stubblefield, W. B.; Baughman, A.; Womack, K. N.; Rhoads, J. P.; Lindsell, C. J.; Hart, K. W.; Zhu, Y.; Olson, S. M.; Kobayashi, M.; Verani, J. R.; Patel, M. M.; Influenza; Network, O. V. i. t. A. I., Association Between mRNA Vaccination and COVID-19 Hospitalization and Disease Severity. JAMA 2021, 326 (20), 2043-2054.

15. Ramesh, S.; Govindarajulu, M.; Parise, R. S.; Neel, L.; Shankar, T.; Patel, S.; Lowery, P.; Smith, F.; Dhanasekaran, M.; Moore, T., Emerging SARS-CoV-2 Variants: A Review of Its Mutations, Its Implications and Vaccine Efficacy. Vaccines 2021, 9 (10), 1195.

16. Alkhatib, M.; Svicher, V.; Salpini, R.; Ambrosio, F. A.; Bellocchi, M. C.; Carioti, L.; Piermatteo, L.; Scutari, R.; Costa, G.; Artese, A.; Alcaro, S.; Shafer, R.; Ceccherini-Silberstein, F.; Perez, D. R., SARS-CoV-2 Variants and Their Relevant Mutational Profiles: Update Summer 2021. Microbiology Spectrum 2021, 9 (3), e01096-21.

17. Wu, F.; Zhao, S.; Yu, B.; Chen, Y. M.; Wang, W.; Song, Z. G.; Hu, Y.; Tao, Z. W.; Tian, J. H.; Pei, Y. Y.; Yuan, M. L.; Zhang, Y. L.; Dai, F. H.; Liu, Y.; Wang, Q. M.; Zheng, J. J.; Xu, L.; Holmes, E. C.; Zhang, Y. Z., A new coronavirus associated with human respiratory disease in China. Nature 2020, 579 (7798), 265-269.

18. Volz, E.; Mishra, S.; Chand, M.; Barrett, J. C.; Johnson, R.; Geidelberg, L.; Hinsley, W. R.; Laydon, D. J.; Dabrera, G.; O’Toole, Á.; Amato, R.; Ragonnet-Cronin, M.; Harrison, I.; Jackson, B.; Ariani, C. V.; Boyd, O.; Loman, N. J.; McCrone, J. T.; Gonçalves, S.; Jorgensen, D.; Myers, R.; Hill, V.; Jackson, D. K.; Gaythorpe, K.; 
Groves, N.; Sillitoe, J.; Kwiatkowski, D. P.; Koshy, C.; Ash, A.; Wise, E.; Moore, N.; Mori, M.; Cortes, N.; Lynch, J.; Kidd, S.; Fairley, D. J.; Curran, T.; McKenna, J. P.; Adams, H.; Fraser, C.; Golubchik, T.; Bonsall, D.; HassanIbrahim, M. O.; Malone, C. S.; Cogger, B. J.; Wantoch, M.; Reynolds, N.; Warne, B.; Maksimovic, J.; Spellman, K.; McCluggage, K.; John, M.; Beer, R.; Afifi, S.; Morgan, S.; Marchbank, A.; Price, A.; Kitchen, C.; Gulliver, H.; Merrick, I.; Southgate, J.; Guest, M.; Munn, R.; Workman, T.; Connor, T. R.; Fuller, W.; Bresner, C.; Snell, L. B.; Patel, A.; Charalampous, T.; Nebbia, G.; Batra, R.; Edgeworth, J.; Robson, S. C.; Beckett, A. H.; Aanensen, D. M.; Underwood, A. P.; Yeats, C. A.; Abudahab, K.; Taylor, B. E. W.; Menegazzo, M.; Clark, G.; Smith, W.; Khakh, M.; Fleming, V. M.; Lister, M. M.; Howson-Wells, H. C.; Berry, L.; Boswell, T.; Joseph, A.; Willingham, I.; Jones, C.; Holmes, C.; Bird, P.; Helmer, T.; Fallon, K.; Tang, J.; Raviprakash, V.; Campbell, S.; Sheriff, N.; Blakey, V.; Williams, L.-A.; Loose, M. W.; Holmes, N.; Moore, C.; Carlile, M.; Wright, V.; Sang, F.; Debebe, J.; Coll, F.; Signell, A. W.; Betancor, G.; Wilson, H. D.; Eldirdiri, S.; Kenyon, A.; Davis, T.; Pybus, O. G.; du Plessis, L.; Zarebski, A. E.; Raghwani, J.; Kraemer, M. U. G.; Francois, S.; Attwood, S. W.; Vasylyeva, T. I.; Zamudio, M. E.; Gutierrez, B.; Torok, M. E.; Hamilton, W. L.; Goodfellow, I. G.; Hall, G.; Jahun, A. S.; Chaudhry, Y.; Hosmillo, M.; Pinckert, M. L.; Georgana, I.; Moses, S.; Lowe, H.; Bedford, L.; Moore, J.; Stonehouse, S.; Fisher, C. L.; Awan, A. R.; BoYes, J.; Breuer, J.; Harris, K. A.; Brown, J. R.; Shah, D.; Atkinson, L.; Lee, J. C. D.; Storey, N.; Flaviani, F.; Alcolea-Medina, A.; Williams, R.; Vernet, G.; Chapman, M. R.; Levett, L. J.; Heaney, J.; Chatterton, W.; Pusok, M.; Xu-McCrae, L.; Smith, D. L.; Bashton, M.; Young, G. R.; Holmes, A.; Randell, P. A.; Cox, A.; Madona, P.; Bolt, F.; Price, J.; Mookerjee, S.; Ragonnet-Cronin, M.; Nascimento, F. F.; Jorgensen, D.; Siveroni, I.; Johnson, R.; Boyd, O.; Geidelberg, L.; Volz, E. M.; Rowan, A.; Taylor, G. P.; Smollett, K. L.; Loman, N. J.; Quick, J.; McMurray, C.; Stockton, J.; Nicholls, S.; Rowe, W.; Poplawski, R.; McNally, A.; Nunez, R. T. M.; Mason, J.; Robinson, T. I.; O’Toole, E.; Watts, J.; Breen, C.; Cowell, A.; Sluga, G.; Machin, N. W.; Ahmad, S. S. Y.; George, R. P.; Halstead, F.; Sivaprakasam, V.; Hogsden, W.; Illingworth, C. J.; Jackson, C.; Thomson, E. C.; Shepherd, J. G.; Asamaphan, P.; Niebel, M. O.; Li, K. K.; Shah, R. N.; Jesudason, N. G.; Tong, L.; Broos, A.; Mair, D.; Nichols, J.; Carmichael, S. N.; Nomikou, K.; Aranday-Cortes, E.; Johnson, N.; Starinskij, I.; da Silva Filipe, A.; Robertson, D. L.; Orton, R. J.; Hughes, J.; Vattipally, S.; Singer, J. B.; Nickbakhsh, S.; Hale, A. D.; Macfarlane-Smith, L. R.; Harper, K. L.; Carden, H.; Taha, Y.; Payne, B. A. I.; Burton-Fanning, S.; Waugh, S.; Collins, J.; Eltringham, G.; Rushton, S.; O’Brien, S.; Bradley, A.; Maclean, A.; Mollett, G.; Blacow, R.; Templeton, K. E.; McHugh, M. P.; Dewar, R.; Wastenge, E.; Dervisevic, S.; Stanley, R.; Meader, E. J.; Coupland, L.; Smith, L.; Graham, C.; Barton, E.; Padgett, D.; Scott, G.; Swindells, E.; Greenaway, J.; Nelson, A.; McCann, C. M.; Yew, W. C.; Andersson, M.; Peto, T.; Justice, A.; Eyre, D.; Crook, D.; Sloan, T. J.; Duckworth, N.; Walsh, S.; Chauhan, A. J.; Glaysher, S.; Bicknell, K.; Wyllie, S.; Elliott, S.; Lloyd, A.; Impey, R.; Levene, N.; Monaghan, L.; Bradley, D. T.; Wyatt, T.; Allara, E.; Pearson, C.; Osman, H.; Bosworth, A.; Robinson, E.; Muir, P.; Vipond, I. B.; Hopes, R.; Pymont, H. M.; Hutchings, S.; Curran, M. D.; Parmar, S.; Lackenby, A.; Mbisa, T.; Platt, S.; Miah, S.; Bibby, D.; Manso, C.; The, C.-G. U. K. c., Assessing transmissibility of SARS-CoV-2 lineage B.1.1.7 in England. Nature 2021, 593 (7858), 266-269.

19. Tegally, H.; Wilkinson, E.; Giovanetti, M.; Iranzadeh, A.; Fonseca, V.; Giandhari, J.; Doolabh, D.; Pillay, S.; San, E. J.; Msomi, N.; Mlisana, K.; von Gottberg, A.; Walaza, S.; Allam, M.; Ismail, A.; Mohale, T.; Glass, A. J.; Engelbrecht, S.; Van Zyl, G.; Preiser, W.; Petruccione, F.; Sigal, A.; Hardie, D.; Marais, G.; Hsiao, M.; Korsman, S.; Davies, M.-A.; Tyers, L.; Mudau, I.; York, D.; Maslo, C.; Goedhals, D.; Abrahams, S.; Laguda-Akingba, O.; Alisoltani-Dehkordi, A.; Godzik, A.; Wibmer, C. K.; Sewell, B. T.; Lourenço, J.; Alcantara, L. C. J.; Pond, S. L. K.; Weaver, S.; Martin, D.; Lessells, R. J.; Bhiman, J. N.; Williamson, C.; de Oliveira, T., Emergence and rapid spread of a new severe acute respiratory syndrome-related coronavirus 2 (SARS-CoV-2) lineage with multiple spike mutations in South Africa. medRxiv 2020, 2020.12.21.20248640.

20. Fiorentini, S.; Messali, S.; Zani, A.; Caccuri, F.; Giovanetti, M.; Ciccozzi, M.; Caruso, A., First detection of SARS-CoV-2 spike protein N501 mutation in Italy in August, 2020. The Lancet Infectious Diseases 2021, 21 (6), e147.

21. Tada, T.; Dcosta, B. M.; Samanovic-Golden, M.; Herati, R. S.; Cornelius, A.; Mulligan, M. J.; Landau, N. R., Neutralization of viruses with European, South African, and United States SARS-CoV-2 variant spike proteins by convalescent sera and BNT162b2 mRNA vaccine-elicited antibodies. bioRxiv 2021.

22. He, X.; Hong, W.; Pan, X.; Lu, G.; Wei, X., SARS-CoV-2 Omicron variant: Characteristics and prevention. MedComm 2021, 2 (4), 838-845.

23. Karim, S. S. A.; Karim, Q. A., Omicron SARS-CoV-2 variant: a new chapter in the COVID-19 pandemic. The Lancet 2021, 398 (10317), 2126-2128.

24. Ali, A.; Vijayan, R., Dynamics of the ACE2-SARS-CoV-2/SARS-CoV spike protein interface reveal unique mechanisms. Scientific Reports 2020, 10 (1), 14214. 
25. Zahradník, J.; Marciano, S.; Shemesh, M.; Zoler, E.; Harari, D.; Chiaravalli, J.; Meyer, B.; Rudich, Y.; Li, C.; Marton, I.; Dym, O.; Elad, N.; Lewis, M. G.; Andersen, H.; Gagne, M.; Seder, R. A.; Douek, D. C.; Schreiber, G., SARS-CoV-2 variant prediction and antiviral drug design are enabled by RBD in vitro evolution. Nature Microbiology 2021, 6 (9), 1188-1198.

26. Zhou, W.; Xu, C.; Wang, P.; Luo, M.; Xu, Z.; Cheng, R.; Jin, X.; Guo, Y.; Xue, G.; Juan, L.; Anashkina, A. A.; Nie, H.; Jiang, Q., N439K Variant in Spike Protein Alter the Infection Efficiency and Antigenicity of SARSCoV-2 Based on Molecular Dynamics Simulation. Frontiers in cell and developmental biology 2021, 9, 697035697035 .

27. Hollingsworth, S. A.; Dror, R. O., Molecular Dynamics Simulation for All. Neuron 2018, 99 (6), 11291143.

28. Wang, E.; Sun, H.; Wang, J.; Wang, Z.; Liu, H.; Zhang, J. Z. H.; Hou, T., End-Point Binding Free Energy Calculation with MM/PBSA and MM/GBSA: Strategies and Applications in Drug Design. Chemical Reviews 2019, 119 (16), 9478-9508.

29. Genheden, S.; Ryde, U., The MM/PBSA and MM/GBSA methods to estimate ligand-binding affinities. Expert opinion on drug discovery 2015, 10 (5), 449-461.

30. Tuccinardi, T., What is the current value of MM/PBSA and MM/GBSA methods in drug discovery? Expert Opinion on Drug Discovery 2021, 16 (11), 1233-1237.

31. Forouzesh, N.; Mishra, N., An Effective MM/GBSA Protocol for Absolute Binding Free Energy Calculations: A Case Study on SARS-CoV-2 Spike Protein and the Human ACE2 Receptor. Molecules 2021, 26 (8). 32. Nguyen, H. L.; Lan, P. D.; Thai, N. Q.; Nissley, D. A.; O'Brien, E. P.; Li, M. S., Does SARS-CoV-2 Bind to Human ACE2 More Strongly Than Does SARS-CoV? J Phys Chem B 2020, 124 (34), 7336-7347.

33. de Andrade, J.; Gonçalves, P. F. B.; Netz, P. A., Why Does the Novel Coronavirus Spike Protein Interact so Strongly with the Human ACE2? A Thermodynamic Answer. ChemBioChem 2021, 22 (5), 865-875.

34. Aljindan, R. Y.; Al-Subaie, A. M.; Al-Ohali, A. I.; Kumar, D. T.; Doss, C. G.; Kamaraj, B., Investigation of nonsynonymous mutations in the spike protein of SARS-CoV-2 and its interaction with the ACE2 receptor by molecular docking and MM/GBSA approach. Comput Biol Med 2021, 135, 104654.

35. Kumar, V.; Singh, J.; Hasnain, S. E.; Sundar, D., Possible Link between Higher Transmissibility of Alpha, Kappa and Delta Variants of SARS-CoV-2 and Increased Structural Stability of Its Spike Protein and hACE2 Affinity. International Journal of Molecular Sciences 2021, 22 (17), 9131.

36. Verma, J.; Subbarao, N., Insilico study on the effect of SARS-CoV-2 RBD hotspot mutants' interaction with ACE2 to understand the binding affinity and stability. Virology 2021, 561, 107-116.

37. Piplani, S.; Singh, P. K.; Winkler, D. A.; Petrovsky, N., In silico comparison of SARS-CoV-2 spike protein-ACE2 binding affinities across species and implications for virus origin. Scientific Reports 2021, 11 (1), 13063.

38. Berman, H. M.; Westbrook, J.; Feng, Z.; Gilliland, G.; Bhat, T. N.; Weissig, H.; Shindyalov, I. N.; Bourne, P. E. The Protein Data Bank. Nucleic Acids Res. 2000, 28 (1), 235-242. https://doi.org/10.1093/nar/28.1.235.

39. Schrödinger Release 2019-3: Protein Preparation Wizard; Epik, Schrödinger, LLC: New York, NY, 2016. Impact, Schrödinger, LLC, New York, NY, 2016; Prime, Schrödinger, LLC, New York, NY, 2019.

40. Søndergaard, C. R.; Olsson, M. H. M.; Rostkowski, M.; Jensen, J. H. Improved Treatment of Ligands and Coupling Effects in Empirical Calculation and Rationalization of PKa Values. J. Chem. Theory Comput. 2011, 7 (7), 2284-2295. https://doi.org/10.1021/ct200133y.

41. Olsson, M. H. M.; Søndergaard, C. R.; Rostkowski, M.; Jensen, J. H. PROPKA3: Consistent Treatment of Internal and Surface Residues in Empirical PKa Predictions. J. Chem. Theory Comput. 2011, 7 (2), 525-537. https://doi.org/10.1021/ct100578z.

42. Harder, E.; Damm, W.; Maple, J.; Wu, C.; Reboul, M.; Xiang, J. Y.; Wang, L.; Lupyan, D.; Dahlgren, M. K.; Knight, J. L.; Kaus, J. W.; Cerutti, D. S.; Krilov, G.; Jorgensen, W. L.; Abel, R.; Friesner, R. A. OPLS3: A Force Field Providing Broad Coverage of Drug-like Small Molecules and Proteins. J. Chem. Theory Comput. 2016, 12 (1), 281-296. https://doi.org/10.1021/acs.jctc.5b00864.

43. D.A. Case, I. Y. B.-S., S.R. Brozell, D.S. Cerutti, T.E. Cheatham, III, V.W.D. Cruzeiro, T.A. Darden, R.E. Duke, D. Ghoreishi, M.K. Gilson, H. Gohlke, A.W. Goetz, D. Greene, R Harris, N. Homeyer, S. Izadi, A. Kovalenko, T. Kurtzman, T.S. Lee, S. LeGrand, P. Li, C. Lin, J. Liu, T. Luchko, R. Luo, D.J. Mermelstein, K.M. Merz, Y. Miao, G. Monard, C. Nguyen, H. Nguyen, I. Omelyan, A. Onufriev, F. Pan, R. Qi, D.R. Roe, A. Roitberg, 
C. Sagui, S. Schott-Verdugo, J. Shen, C.L. Simmerling, J. Smith, R. Salomon-Ferrer, J. Swails, R.C. Walker, J.

Wang, H. Wei, R.M. Wolf, X. Wu, L. Xiao, D.M. York and P.A. Kollman, AMBER 2018, University of California, San Francisco, 2018.

44. Götz, A. W.; Williamson, M. J.; Xu, D.; Poole, D.; Le Grand, S.; Walker, R. C. Routine Microsecond Molecular Dynamics Simulations with AMBER on GPUs. 1. Generalized Born. J. Chem. Theory Comput. 2012, 8 (5), 1542-1555. https://doi.org/10.1021/ct200909j.

45. Salomon-Ferrer, R.; Götz, A. W.; Poole, D.; Le Grand, S.; Walker, R. C. Routine Microsecond Molecular Dynamics Simulations with AMBER on GPUs. 2. Explicit Solvent Particle Mesh Ewald. J. Chem. Theory Comput. 2013, 9 (9), 3878-3888. https://doi.org/10.1021/ct400314y.

46. Maier, J. A.; Martinez, C.; Kasavajhala, K.; Wickstrom, L.; Hauser, K. E.; Simmerling, C. Ff14SB: Improving the Accuracy of Protein Side Chain and Backbone Parameters from Ff99SB. J. Chem. Theory Comput. 2015, 11 (8), 3696-3713. https://doi.org/10.1021/acs.jctc.5b00255.

47. Kirschner, K. N.; Yongye, A. B.; Tschampel, S. M.; González-Outeiriño, J.; Daniels, C. R.; Foley, B. L.; Woods, R. J. GLYCAM06: A Generalizable Biomolecular Force Field. Carbohydrates. Journal of Computational Chemistry 2008, 29 (4), 622-655. https://doi.org/10.1002/jcc.20820.

48. Jorgensen, W. L.; Madura, J. D. Quantum and Statistical Mechanical Studies of Liquids. 25. Solvation and Conformation of Methanol in Water. J. Am. Chem. Soc. 1983, 105 (6), 1407-1413. https://doi.org/10.1021/ja00344a001.

49. Pettersen, E. F.; Goddard, T. D.; Huang, C. C.; Couch, G. S.; Greenblatt, D. M.; Meng, E. C.; Ferrin, T. E. UCSF Chimera-A Visualization System for Exploratory Research and Analysis. J. Comput. Chem. 2004, 25 (13), 1605-1612. https://doi.org/10.1002/jcc.20084.

50. Goddard, T. D.; Huang, C. C.; Meng, E. C.; Pettersen, E. F.; Couch, G. S.; Morris, J. H.; Ferrin, T. E. UCSF ChimeraX: Meeting Modern Challenges in Visualization and Analysis. Protein Sci. 2018, 27 (1), 14-25. https://doi.org/10.1002/pro.3235.

51. Miller, B. R.; McGee, T. D.; Swails, J. M.; Homeyer, N.; Gohlke, H.; Roitberg, A. E. MMPBSA.Py: An Efficient Program for End-State Free Energy Calculations. J. Chem. Theory Comput. 2012, 8 (9), 3314-3321. https://doi.org/10.1021/ct300418h.

\section{Author Contributions}

The study was conceived by all authors; CC and JA ran the simulations and performed the analyses. All authors wrote the main manuscript and SI. All authors reviewed all documents.

\section{Competing Interests}

The authors have no competing interests to declare. 